\title{
A PROPÓSITO DEL CRUCIFICADO DE BERNINI EN EL ESCORIAL: EL CRUCIFIJO DE CARTAPESTA DEL CARDENAL SFORZA PALLAVICINO
}

\author{
RuBÉN LÓPEZ CONDE \\ Universidad de Jaén
}

\begin{abstract}
El presente artículo pretende completar la historia del Crucificado realizado por Bernini para el Panteón de Reyes de El Escorial. El hallazgo de documentación relativa a un segundo Crucifijo simile, ya citado por Baldinucci, y sobre el que la historiografía no había hecho sino especular, ayuda a cerrar una de las incógnitas hasta ahora abiertas en torno al bronce madrileño. La singularidad de este segundo ejemplar -en realidad, un modelo policromado ejecutado en cartapesta-, permitirá penetrar por entre las fases del proceso escultórico, al tiempo que revalorizar las obras realizadas en este envilecido material.
\end{abstract}

Palabras clave: Bernini; El Escorial; Pallavicino; Tomasi; Modelo; Cartapesta; Crucifijo.

\section{ON BERNINI'S CHRIST CRUCIFIED IN THE ESCORIAL: THE CARTAPESTA CRUCIFIXION OF CARDINAL SFORZA PALLAVICINO}

This article attempts to complete the history of the Christ Crucified by Bernini carried out for the Pantheon of the Kings at The Escorial. The discovery of documentation concerning a second Crucifix simile (mentioned by Baldinucci, but about which historians had merely speculated), helps to resolve one of the remaining mysteries relating to the Madrid bronze. The singularity of this second example -in fact, a polychrome model made of cartapesta- allows us to penetrate into the sculptural process as well as to revalue works executed in this degraded material.

Key words: Bernini; The Escorial; Pallavicino; Tomasi; Model; Cartapesta; Crucifix.

Tres veces se refiere Baldinucci al crocifisso di bronzo que con destino al Panteón de Reyes de El Escorial elaboró Gian Lorenzo Bernini a solicitud de Felipe IV (fig. 1). La primera, y más importante, da cuenta de su ejecución: "E condusse ad istanza del Re delle Spagne Filippo IV, un gran Crocefisso di bronzo, che ebbe suo luogo nella Capella de'Sepolcri de'Re"1; referencia asimismo encuadrada por

\footnotetext{
${ }^{1}$ BaldinucCI, F., Vita del Cavaliere Gio Lorenzo Bernino, Florencia, 1682, p. 37. Y en similares términos, si bien informando de la entrega de una gran Collana d'oro per honorario, lo reseña el segundo gran biógrafo del artista, el sexto de sus hijos, Domenico BerninI: Vita del Cavalier Gio. Lorenzo Bernino, Roma, 1713, p. 64.
} 
dos largas citas que permiten ensayar una probable datación: la superior, referida a las postrimerías del pontificado de Inocencio X, muerto en enero de $1655^{2}$; la inferior, al inicio del epistolado de Alejandro VII ${ }^{3}$. La obra pues sería ejecutada poco antes de la muerte del Pontífice hispanófilo Giovanni Battista Pamphili (y probablemente recibida en Madrid una vez inaugurado el Panteón escurialense) ${ }^{4}$.

A la segunda de las citas contenidas en la Vita del Cavaliere me referiré más adelante. En cuanto a la última, un corto asiento dentro del largo elenco de obras ejecutadas por el Caballero y listadas, a modo de colofón, por el biógrafo florentino, permite conocer un nuevo aspecto del Crucifijo: fue ejecutado a tamaño natural (en realidad, algo menor que el natural) ${ }^{5}$.

Todos estos datos remiten inequívocamente al Crucificado que por brevísimo tiempo ocupó el altar del Panteón Real escurialense (con la llegada en 1659 del Cristo de Domenico Guidi sería trasladado a la Sacristía del Colegio) ${ }^{6}$, y descrito ya en la temprana fecha de 1657 por el padre Santos, aun sin citar su renombrada autoría: "Es este Crucifixo de Bronce, de cinco pies de alto, y de tan excelente hechura, que seràn pocas, ò ninguna, las que llegaren à su primor y valentia; hizose en Roma"'.

Hasta aquí, no parecen existir demasiadas dudas respecto de la comisión, autoría, datación y destino de la obra. Pero es en este punto que se impone la tempranísima monografía de Stanislao Fraschetti, que viene a impugnar la información suministrada por los primeros historiadores ${ }^{8}$. Siguiendo las tesis del italiano, nuestro Crucificado ya no habría sido encargado por el monarca Austria, sino por Inocencio X, "che lo regalò rinchiuso in una richissima cassa, insieme con altri doni, a Maria Anna d'Austria"; aseveración que funda en una entrada del diario romano de Giacinto Gigli de 1649: "Papa Innocentio X mandò il Cardinale ludoviso suo parente, legato da latere a Milano a fari i complimenti con Maria Anna d'Austria [...] che era giunta in Milano. et a di 4 agosto il d. ${ }^{\circ}$ Cardinale fece l'offitio, et donò alla Regina da parte dal Papa un Corpo Santo dentro una ricchissima cassa..." . No obstante sus terminantes conclusiones, no parece fácil deducir qué relación observó Fraschetti entre el Corpo Santo presentado a Mariana -si con la dicha denominación el diarista Gigli quiso referirse a un crucifijo de bronce ${ }^{10}-\mathrm{y}$ el quehacer de Bernini ${ }^{11}$.

\footnotetext{
2 "Appressavasi il fine di quel Pontificato, quando al Bernino venne fatto di stringer vie più l'antica amicizia, che egli aveva avuto con Monsig. Fabio Ghigi, tornato appunto allora dalla Nunziata di Colonia...”, BALDINUCCI, F. (1682), Op. cit., p. 36.

3 "Non era ancora tramontano il Sole di quel giorno, che fu primo al Cardinal Ghigi nella sovranissima dignità di Sommo Pontefice". Ibidem, p. 37.

${ }^{4}$ Cfr. Checa, F., "El triunfo del catolicismo (Bernini: 1650-1680)", en AA.VV., Cortes del Barroco. De Bernini y Velázquez a Luca Giordano, Madrid, 2003, pp. 206-207.

5 "Crocifisso grande quanto il naturale per l'Altare della Capp. Reale di Filippo IV. Madrid". BALdinUCCI, F. (1682), Op. cit., p. 106. Las dimensiones del Cristo son las siguientes: $140 \times 120 \times 34 \mathrm{~cm}$.

${ }^{6}$ Para conocer los diferentes trasiegos a que se vieron sometidos los crucifijos de bronce de El Escorial, ver: Tormo, E., "Los cuatro grandes Crucifijos de bronce dorado del Escorial", Archivo Español de Arte y Arqueología, 2, 1925, pp. 117-145.

7 De los Santos, F., Descripción breve del Monasterio de S. Lorenzo el Real del Escorial..., Madrid, 1657, p. 134.

${ }^{8}$ Fraschetti, S., Il Bernini. La sua vita, la sua opera, il suo tempo, Milán, 1900. Dada la dificultad para acceder a un ejemplar de esta obra, las citas han sido extraídas del extenso estudio elaborado por Elías Tormo: Op. cit., pp. 139-140.

9 Ibidem, p. 139.

${ }^{10}$ Una suspicacia en relación a esta identificación igualmente levantada por María Elena Gómez-Moreno, para quien la expresión corpo santo aludiría simplemente a una reliquia. Gómez MorENO, M. E., "La escultura religiosa y funeraria en El Escorial”, en AA.VV., El Escorial. IV Centenario de la fundación del Monasterio de San Lorenzo el Real, Madrid, 1964, p. 512.

${ }_{11}$ El razonamiento de Fraschetti parece encontrar asiento en las palabras de Carl Justi, que, en su celebrado estudio sobre Velázquez, afirma que Bernini "hizo en 1649 un crucifijo de bronce para la joven reina, que pagó Felipe IV con una cadena de oro". Justi, C., Velázquez y su siglo, Madrid, 1999 (1.a ed. 1888), p. 469. Sólo así puede entenderse la vinculación entre la fecha de 1649, la Reina Mariana, la nota en el diario de Gigli y la autoría de Bernini.
} 


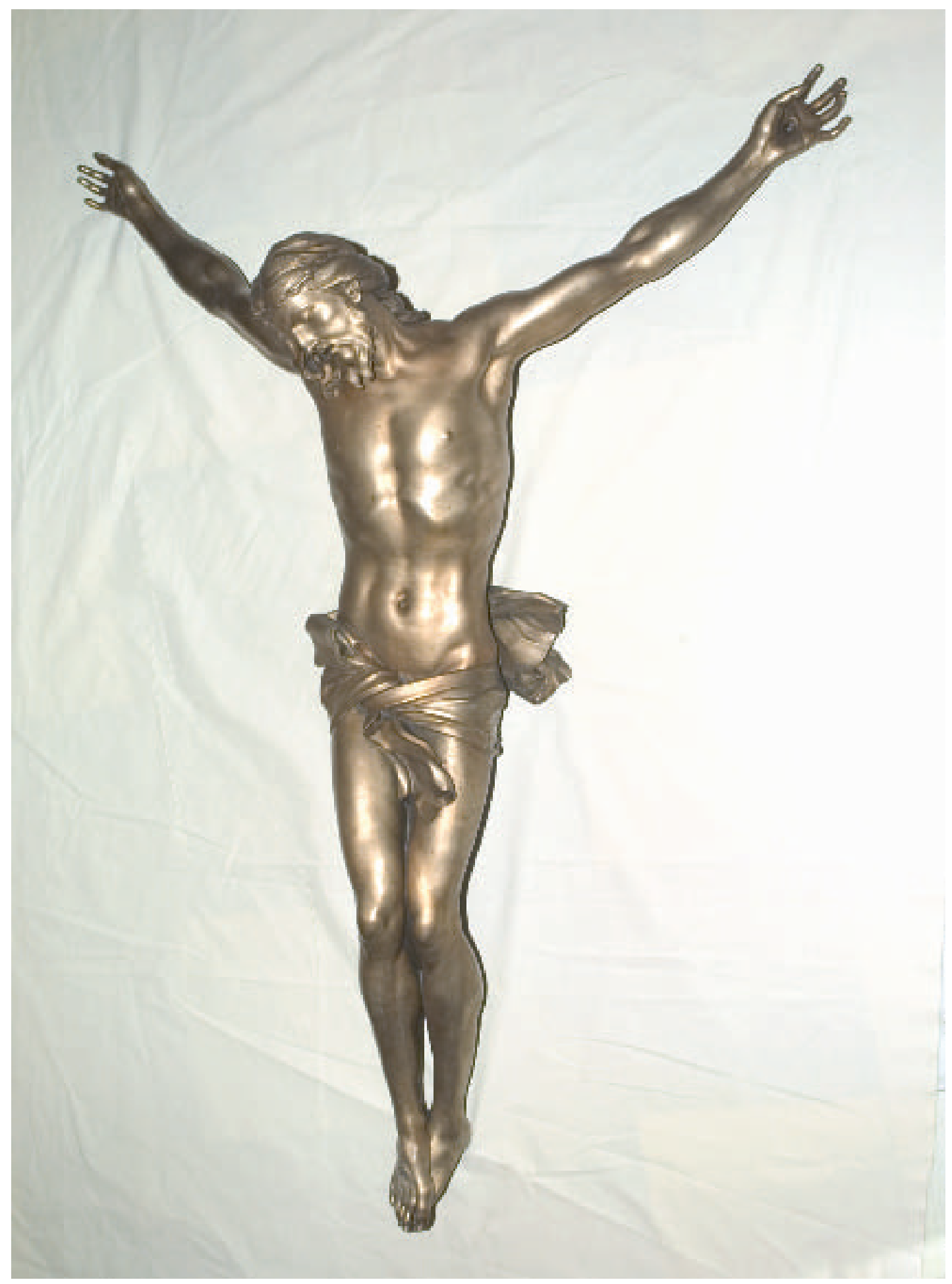

Fig. 1. G. L. Bernini. Cristo Crucificado. Bronce. Monasterio de El Escorial. Copyright (C) Patrimonio Nacional.

Arch. esp. arte, LXXXIV, 335, JULIO-SEPTIEMBRE 2011, 211-226, ISSN: 0004-0428 
Elías Tormo alimenta más la confusión con una aventurada teoría -sobre la base de segundas afirmaciones del italiano- respecto de la procedencia y comisión del crucifijo, que ahora habría sido elaborado en tiempos de Urbano VIII ${ }^{12}$ y regalado por su sucesor y antagonista Inocencio X, a fin de hacer un "regalo barato, y de sonora esplendidez, nada menos que "un crucifijo de tamaño natural de Lorenzo Bernini en bronce dorado', y de paso mataba (cual tuvo frecuente empeño) otro de los recuerdos del Papa Barberino. Y todavía más, pues hay que decirlo todo, regalaba un Bernini que probablemente había gustado poco en Roma"13.

Rudolf Wittkower, en su referencial trabajo sobre el poliédrico artista napolitano, ni tan siquiera presta oídos a sendas teorías, fijando, sobre la base de lo ya apuntado por Baldinucci, la fecha de 1654 y la comitencia del Cuarto Felipe $^{14}$, particulares que han quedado para la mayor parte de la ulterior crítica ${ }^{15}$.

Pero aquí no acaba la polémica. En 1998, Francesco Petrucci relaciona, no sin cierto fundamento, varias entradas del críptico diario de Fabio Chigi con la Croce escurialense (aun cuando ninguna de las anotaciones alude a este preciso destino o promueve la identificación con el Crucificado español). Siguiendo el tenor de los asientos, el 8 de febrero de 1654, el todavía Cardenal Chigi recibe la visita del escultor, que porta consigo una Cruz (sobre la que nada se especifica) ${ }^{16}$. Durante las siguientes jornadas (si bien ninguna otra entrada vuelve a referirse a esta enigmática pieza), el diario registra una intensificación de los contactos con el flamante embajador español ante la Santa Sede, don Diego de Aragón, IV Duque de Terranova (lo que cabe juzgar del todo lógico, por cuanto el español inicia su legacía ${ }^{17}$ y Chigi ocupa la Segretaria di Stato vaticana, además de ser, como bien recuerda Petrucci, confidente y brazo derecho en política exterior del

12 Fraschetti documenta un primer crucifijo de bronce realizado por Bernini ya en los albores del pontificado de Urbano VIII, "da dedicarsi al medesimo Salvatore vicino alla Porta Santa [de San Pedro Vaticano]". Su ausencia en este punto y el entonces desconocimiento de otros Crucificados vinculados al hacer de Bernini, le lleva a especular con que fuese bien el entregado a Felipe IV, bien el crocifisso simile que debió poseer el Cardenal Pallavicino (al que más tarde aludiré). Esta reflexión dará fundamento a las apreciaciones de ToRmo: Op. cit., pp. 139-140.

13 Ibidem.

14 Wittkower, R., Gian Lorenzo Bernini. El escultor del barroco romano, Madrid, 1990, pp. 264-269.

15 No obstante algunas reputadas excepciones: Rodríguez Gutiérrez de Ceballos, en su seguimiento del ascendente berniniano en España, magnífico estudio prologal a la monografía de Hibbard sobre el artista, se hace eco de las palabras de Baldinucci y de las noticias aportadas por Fraschetti a propósito de la entrega del crucifijo a Mariana de Austria, lo que "parece históricamente más verosímil, pues resulta difícil de comprender que, dada la tirantez de relaciones existentes entre el monarca español y Urbano VIII, aquél hubiera encargado un crucifijo nada menos que para el Panteón de El Escorial al escultor más descaradamente protegido por su rival”. Sin embargo, lo que la biografía de Baldinucci reporta no es, como hemos podido comprobar, un crucifijo obrado durante el episcopado del Papa Barberini, sino una escultura ejecutada en las postrimerías del gobierno pontificio de Inocencio X. La confusión del docto historiador viene sin duda alentada por la rebuscada teoría de Tormo, a quien igualmente menciona: RodríGuez G. DE CeBALlos, A., "La huella de Bernini en España", en HibBard, H., Bernini, Madrid, 1982, p. 10. Por otro lado, no parece muy acertada la lectura de las fuentes llevada a cabo por F. Niño, que refiere como cita de Baldinucci la entrega del crucifijo a Mariana: NiÑo, F., "Bernini en Madrid", Archivo Español de Arte, 69, 1945, p. 150; error que recoge Portela SANDOVAL: "Varia sculptorica escurialensia", en CAMPOS Y FERnÁNDEZ, F. J. (Coord.), La escultura en el Monasterio del Escorial. Actas del Simposium, El Escorial, 1994, p. 250.

${ }^{16}$ Petrucci, F., "Bernini, Algardi, Cortona ed altri artisti nel diario di Fabio Chigi Cardinale (1652-1655)", Rivista dell'Istituto Nazionale di Archeologia e Storia dell'Arte, 21, 1998 (2000), pp. 190-192. La lacónica entrada de 8 de febrero de 1654 reza así: "8. D[ome]nica d[etto] $\mathrm{m}[$ ese]... è da me... Cav. Bernino con la croce". Petrucci presume, a partir de la fecha en que tiene lugar el encuentro y los ulteriores contactos con el embajador español, que debe tratarse del Crucifijo que será enviado a El Escorial. Justifica el uso del término Croce por las dimensiones casi naturales del Cristo.

17 Terranova fue el embajador español en Roma entre febrero de 1654 y junio de 1657. García Cueto, D., "Don Diego de Aragón, IV Duque de Terranova, y el envío de esculturas para Felipe IV durante su embajada (1654-1657)", Archivo Español de Arte, 311, 2005, p. 317. 
Pontífice ${ }^{18}$; finalmente, el 9 de marzo tiene lugar el decisivo encuentro entre los tres presuntos implicados (del que nada trasciende) ${ }^{19}$. A partir de estas escuetas referencias, su datación y la hipotética ronda de reuniones, Petrucci no sólo procede a identificar la pieza, sino que avanza la audaz teoría de la intermediación del Cardenal en la comisión, que corre - una vez más- por cuenta de Inocencio X: "Il dono sembrerebbe così potersi inquadrare in un azione politica di distensione con la monarchia spagnola, promossa dal Segretario di Stato, a seguito del [...] grave incidente avvenuto nel mese di gennaio, che causò l'espulsione il 3 febbraio del card. Camillo Astalli Pamphili" ${ }^{20}$.

Finalmente, en 2005, García Cueto resuelve esta animada controversia, haciendo pública la cuenta de gastos de la embajada del Duque de Terranova que certifica la positiva comisión del bronce por el monarca hispano: un pago de mil escudos realizado a Il Cavaliere "por la obra del Santo Cristo que S.M. me mando hacer" 21 ; asimismo, el documento refiere sucintamente los avatares de su traslado a la Península: portado en carruaje hasta el puerto de Civitavecchia, embarcado rumbo a Alicante y finalmente trasladado a Madrid, todo lo cual costó 225 escudos $^{22}$.

Hasta aquí, parecen disiparse las incógnitas históricas en torno a la más conocida obra de Bernini en España ${ }^{23}$; y así viene a corroborarlo la documentación que hoy se evalúa, que redunda en el destino de la pieza - per il nostro Filippo $I V-$ y en la mediación de la sede diplomática española -ad istanza del signor Ambasciatore-. No obstante, antes de penetrar en su análisis, conviene referir la ya casi olvidada segunda cita de Baldinucci a propósito del bronce español; una cita que curiosamente desvía la atención hacia un ejemplar simile en posesión del Cardenal Sforza Pallavicino y que asimismo ha venido a generar una cierta controversia ${ }^{24}$ :

“Aveva il Cavaliere fatto per la Maesta del Re di Spagna il Crociffiso di bronzo, di che altra volta abbiam parlato; ed un'altro simile ne avea condotto per se medesimo, e mentre ei si trovava in Francia [1665], ordinò a i suoi, che lo donassero al Cardinal Pallavicino. Occorse poi, che lo stesso Cardinale parlando col Bernino, non finiva di lodare la bellezza del Crocifisso; al che rispose il Cavaliere: io dirò a V.E. quel ch'io dissi in Francia alla Maesta della Regina, mentre ella altamente mi lodava il ritratto del Re suo Marito: V.M. loda tanto la copia, perchè ella è innamorata dell'originale".

Como acertadamente advertía Wittkower, la redacción de este párrafo no dejaba de resultar algo confusa: ¿a qué se refería Baldinucci con el término simile? ¿Aplicaba el biógrafo los cri-

\footnotetext{
18 Recojo aquí las entradas del diario que aluden a los encuentros entre el Cardenal y el embajador español (PETRUCCI, Op. cit., p. 196): 21. Sabbato... è da me... V. Ab. Michelij circa il mandar S. Ec.a la carrozza incontro all Ambas.e di Sp.a. / 22. D.nica... à 21/2... Amb.e di Spagna N. S. / 1 di Marzo... esco p salire a 21. col Cini torno a 23 d.o. è su con le altri, l’Amb.e di Sp.a... / 7. Sabb.o... a 22. È dà me il D.di Terranova Amb.e Straord. di Sp.na, il sottodatario, il P. Sforza Pallav.no.

199 di Marzo. Lunedi d. m... parlo al D. Sp[agn]a a M.r Teor.o [?], Cav. Bernino, entro a 2. Esco a s[era]. Ibidem, pp. 192 y 196. Nada hace suponer que el tema de las conversaciones (si verdaderamente tuvieron lugar: el cripticismo del diario ni siquiera permite asegurar la efectividad del encuentro) girase en torno a la mentada Croce; una pieza de la que se desconoce, por otro lado, cualquier particular (vinculante o no).

20 Ibid., p. 192. La hipótesis de Petrucci parece sugerida por los postulados de Fraschetti y Tormo.

${ }^{21}$ García Cueto, D., Op. cit., pp. 317-318.

22 Archivo General de Simancas, Tribunal Mayor de Cuentas, 2634. Cuentas de don Diego de Aragón, duque de Terranova, durante su embajada en Roma, 1654-1657. Año 1657. Cit. en: Ibid.

${ }^{23}$ Respecto de su relación artística con nuestro país, véanse: Rodríguez G. DE Ceballos, A., Op. cit. y Rodríguez RuIz, D., "Sobre el modelo de bronce de la Fontana dei Quattro Fiumi de Gian Lorenzo Bernini conservada en el Palacio Real de Madrid", Reales Sitios, 155, 2003, pp. 29-44.

${ }^{24}$ BaldinucCi, F. (1682), Op. cit., p. 74.
} 
terios del moderno historiador del arte? Sea como fuere, la crítica dio por sentado que el Crucifijo entregado a Pallavicino debió ser una obra igualmente vaciada en bronce ${ }^{25}$; particular que de ninguna manera parecía evidente ${ }^{26}$. La cuestión, entretanto no se localizase el reseñado Crucifijo o apareciesen nuevos testimonios, estaba lejos de poder solucionarse. En 1955, Federico Zeri creyó descubrir el misterioso bronce en la capilla del Palacio Pallavicini-Rospigliosi de Roma. Sin embargo, como oportunamente anotaba Wittkower, el Cristo del Escorial y el Pallavicini "difícilmente podían ser más distintos. Este último es en tamaño la mitad que el primero [72,4 cm.]; el crucifijo español representa a un Cristo muerto, el crucifijo Pallavicini al Cristo vivo y sufriendo; los prototipos faciales son diferentes; el cuerpo de uno oscila hacia la izquierda, el del otro hacia la derecha [...] un espíritu totalmente distinto anima [sus ropajes]"27. O Baldinucci había utilizado el término simile con asombrosa libertad, o sendas obras nunca habían mantenido una relación pretérita ${ }^{28}$. Y como ha demostrado la ulterior crítica, ni siquiera hoy cabe mantener esta atribución; los argumentos en favor de su restitución a Algardi parecen incontrovertibles ${ }^{29}$.

Descartado pues el Crucificado del Palacio Pallavicini, durante largo tiempo ningún otro vino a reclamar la vieja filiación escurialense. En 1997, Tomaso Montanari pareció hallar solución a este viejo enigma, servido a este fin -todo sea dicho- de fundamentos absolutamente convincentes. El historiador italiano consiguió individuar la desaparecida obra entre los bienes legados por Pallavicino a su muerte; así rezaba una de las disposiciones testamentarias del finado (dadas el 4 de junio de 1667, día anterior a su fallecimiento): "aggiungo al legato del [...] signor Stefano [Pignatelli] il Crocifisso grande datomi dal monsignor Bernino [se refiere al eclesiástico Pier Filippo, primogénito de Gian Lorenzo y discípulo de Sforza en los primeros años 60$]^{30}$, ch'io tengo nell'anticamera" 31 . Aunque exigua (desde nuestro ventajoso punto de vista), esta sucinta referencia parecía del todo suficiente para corroborar la información suministrada por Baldinuc-

${ }^{25}$ Como había hecho, por ejemplo, el mismo WitTKower, Op. cit., pp. 267-268.

${ }^{26}$ Como verifican los documentos que hoy se presentan. Conviene no obstante señalar que pese a los límites inciertos en que por definición se mueve el adjetivo simile, este vocablo parece privilegiar antes lo formal e iconográfico que lo material (éste sería el adjetivo que cabría aplicar por ejemplo al modello en cartón-piedra del Alma Condenada del propio Bernini, hoy conservado en el Museo Cívico de Perugia, con el que el ejemplar definitivo no comparte ni médium, ni color). Por otro lado, en el texto del biógrafo, el sintagma di bronzo aparece vinculado al crucifijo del monarca español; nada parece indicar (como tampoco excluir) que sea extensivo a un'altro simile.

27 Italo Faldi dio a conocer la opinión de Zeri en: "Berniniana: un nuovo libro e una scultura inedita", Paragone, 71, 1955, p. 52; WitTKOWER, R., Op. cit., p. 268.

${ }^{28}$ Como apropiadamente apuntilló Tomaso Montanari, un simple argumento histórico hubiese bastado para romper el vínculo reseñado por Zeri, a saber: en el Seicento no existía relación alguna entre la rama parmesana de los Pallavicino, a la que pertenecía Sforza, y la genovesa, instalada entonces en el palacio del Monte Quirinal. "Gian Lorenzo Bernini e Sforza Pallavicino", Prospectiva, 87-88, 1997, p. 50.

29 Nava Cellini, A., "Note per l'Algardi, il Bernini e il Reni”, Paragone, 207, 1967, pp. 35-41; Johnston, C., "Drawings for Algardi's 'Cristo Vivo"”, The Burlington Magazine, 785, 1968, pp. 459-460. A los argumentos en contrario proporcionados por Wittkower, estilísticos e históricos (pese a que el profesor alemán propone asimismo argumentos en favor de su atribución a Bernini), cabe añadir el descubrimiento de varios dibujos y grabados que vinculan el Crucifijo del Palacio Pallavicini con el hacer de Algardi; existe asimismo un considerable número de versiones de esta obra tradicionalmente atribuidas al boloñés.

${ }^{30}$ Como informa Montanari, la probada lealtad de Pallavicino movió a Bernini a confiarle, a comienzos de los 60 , la formación de su propio primogénito; una formación que debía favorecer no tanto su carrera curial o su educación teológica, como sus dotes literarias (de las que ya había dado cumplida cuenta). Cfr. MontanARI, T., Op. cit., p. 47. Virtudes literarias a las que se refiere el mismo Baldinucci: "Pier Filippo suo fligliuolo, oggi degno Prelato della Corte di Roma, il quale avendo [...] un bel genio di eroica Poesia saputo a maraviglia congiugnere lo studio delle buone lettere, non lascia in questi nostri tempi di farsi conoscere degno erede delle sublimissime abilità d'un tanto Padre". BALDINUCCI, F. (1682), Op. cit., p. 23.

31 Montanari, T., Op. cit., p. 50. 
ci -que algunos habían llegado a poner en duda o rechazar ${ }^{32}-$ y reconocer en el Crucifijo entregado por el hijo del artista, la tan traída segunda pieza citada por el biógrafo. En este sentido, la mención a Monsignor Bernino encontraba plena justificación no sólo en las palabras de Baldinucci (que especificaba que habían sido $i$ suoi los encargados de entregar la obra al Cardenal Sforza), sino también en el papel intermediador que durante la estadía francesa del Caballero había desempeñado el eclesiástico entre padre y maestro ${ }^{33}$. En este orden, era lógico deducir la identidad de sendos Crucifijos.

No obstante la dificultad para refutar esta línea argumental o el peso de sus factores concurrentes, la cita no dejaba de resultar algo vaga. Aunque era lógico presuponer la autoría del Crucifijo donado por Pier Filippo, nada se especificaba sobre este particular; como tampoco respecto de su pretérita relación con la pieza escurialense. Nada pues impedía pensar en cualquier otro Crucifijo, berniniano o no, regalado al Cardenal por un agradecido discípulo. Asimismo, podía extrañar que, dado el orgullo con que el prelado jesuita refería a Gian Lorenzo, la estima con que siempre acogía su obra y el inigualable prestigio de que gozaba el escultor, Pallavicino escamotease la referencia a tan preciada autoría; más, cuando así se había conducido con las restantes tres obras del napolitano conservadas a su muerte: "A monsignor Giuseppe della Cornia [...] un ritratto fatto a penna dal cavalier Bernino del glorioso San Gioseppe"; "A monsignor Casanatta [...] un ritratto di papa Alessandro fatto a penna dal cavalier Bernino con esquisita diligenza"; y "A monsignor Giovanni Antonio Melzi [...] un mio ritratto delineato dal cavalier Bernino" ${ }^{34}$. Elusión tanto más asombrosa para el caso de su particular heredero, el literato Stefano Pignatelli, que días después de la apertura del testamento, requería del secretario de Pallavicino la entrega de un exiguamente referido Crucifijo, "lasciatomi per legato dalla benedetta anima del signor cardinale" 35 .

Sea como fuere, nuestros reparos difícilmente pasan de meras conjeturas; se hacen precisas pruebas más sólidas con que sustentar una tesis rupturista. Y es en este punto que cabe insertar un primer documento, que si bien no enteramente inédito, hasta hoy -y hasta donde yo sé- había pasado desapercibido a la historiografía artística: una carta fechada hacia finales de junio de 1667 -apenas veinte días después de la muerte del Cardenal-y enviada por el clérigo teatino Carlo de Tomasi a su hermano Giulio, I Duque de Palma di Montechiaro y futuro Príncipe de Lampedusa ${ }^{36}$ :

32 Sin llegar a negar la veracidad de la noticia aportada por Baldinucci, Tormo interpreta el particular como un deseo de anécdota y una rebuscada muestra del ingenio que debió presidir las conversaciones entre biógrafo y escultor. Op. cit., p. 141, NPP. Más concluyente (y errada, como justifica Montanari y corrobora la documentación) se manifiesta Sandrina Bandera a propósito de esta información; de acuerdo con la italiana, "un documento inedito [...] scritto con grafia di difficile, ma non imposibile lettura, proverà senza ombra di dubbio che il Bernini da Parigi ordinò di donare al cardinale non un crocifisso, ma il 'Ritratto di N.S (cioè di Alessandro VII), piccolo fatto in lapis con una piccola cornice di ebano cha ha cristallo"”. Cita extraída de: Montanari, T., Ibidem, p. 66, nota 53.

33 Ibid., pp. 48-49.

${ }^{34}$ Ibid., p. 49.

${ }^{35}$ Ibid., p. 66, nota 66.

${ }^{36}$ Archivo General de los Padres Teatinos, Roma: Ms. 233, f. 237. Carta de Carlo de Tomasi al Duque de Palma; 26 de junio de 1667. Aparecida en una limitadísima edición del epistolario familiar inédito del clérigo, de tan menguada tirada que, de acuerdo con el Padre Bartolomé de Sant'Andrea della Valle, a quien debo esta información, la Casa Generalicia de la Orden apenas posee un par de copias impresas; las misivas fueron catalogadas y transcritas por Giuseppe Mangiavillano, viendo la luz (si estos términos resultan apropiados) en 2004: Tomasi, C., Lettere Familiari (1642-1674), Roma, 2004. Para paliar esta situación, el texto íntegro de aquel volumen ha sido recientemente volcado a la Red, en una suerte de Biblioteca Digital de la devota familia Tomasi. Entre otros documentos, pueden consultarse las biografías íntegras de sus primeros miembros, algunos de sus trabajos literarios y una abundante muestra de la correspondencia conservada en archivo: $<$ http://www.infolio.it/tomasi.html $>$. 
"Mando a V.S. copia del capitolo del testamento della s.m. del signor Card. Pallavicino, e conserverò le sante reliquie per le VV.SS. e con prima comodità di mare, manderò alla signora Duchessa una gioia singolarissima che detto Signore mi aveva dato prima di morire. Questo è un Crocifisso di carta pesta, modello del signor Cavaliere Bernino, il quale ne fece uno simile di bronzo per il nostro Re Filippo IV, ad istanza del signor Ambasciatore, che è stata una cosa celebratissima per la corte di Roma, e di Spagna; ma io ho detto che stimo più il mio, perché nel bronzo si vede solo l'eccellenza del lavoro, ma qui con il colorito della carnagione si muove a meraviglia l'effetto; tanto maggiore, che Monsignor [Pier Filippo] Bernino l'ha fatto rifare più volte per renderlo più vivamente devoto; in particolare è meravigliosa la SS.ma faccia, che negli altri dolori spiega una allegrezza di Paradiso, e il signor Cavaliere mi ha detto, che egli non può capire di vedere il Crocifisso col volto malinconico, e con tutto si studia di farlo allegro, mai si può saziare, e resterà vederlo nel Paradiso. Io non l'ho mandato avanti, perché il signor Cardinale favorendomi di venire in cella, non avrebbe avuto per bene che io me lo fossi tolto, avendomelo egli stesso portato di persona, né io ce l'ho avvisato, per non le dare una santa invidia, adesso che quello è andato in Paradiso, ho preso licenza dal Superiore, stimando guadagno con mandarlo alla signora Duchessa, perché lo godrà col mezzo delle sue orazioni, voglio però che lo conservi in qualche tabernacolo coperto, e che lo scopra solo a tempo di orazioni, e quando tiene aridità di spirito, perché in vedere quel santo volto tutto si riempirà di allegrezza... [sigue con otros particulares]".

Pese a la aparente elocuencia del texto, son precisas algunas matizaciones que ayuden a completar su significado. En primer lugar, respecto de la relación que unió a un poco conocido Tomasi con el resto de personajes en concurrencia; relación que en ambos casos se descubre tan próxima como la misiva sugiere. De la profunda y sincera amistad que unió a sendos religiosos da cumplida cuenta un hecho: fue el clérigo teatino quien asistió a Pallavicino en sus instantes postreros ${ }^{37}$. Si esto no fuera suficiente, a Tomasi dedicó el tercer libro de su Arte della Perfezion Cristiana, publicado en Roma en $1665^{38}$. Y como cabía esperar de persona que fue tan desprendida (y así lo hace ver su biografía), nuestro Crucifijo no fue el único presente que la familia Tomasi recibió del prelado jesuita $^{39}$ : entre otros, la documentación refiere una imagen de plata enviada al Duque a mediados de 1666 (y que fue correspondida con otra de oro) ${ }^{40}$ o la donación de las más diversas reliquias ${ }^{41}$.

${ }^{37}$ Así lo refirió Affó en su Vita del Cardinale: "Aggravatosi dunque il suo male, e sentendo vicino il momento estremo, volle al suo fianco il padre Alessandro Fieschi suo confesore [...], e il prelodato venerabile padre Carlo Tommasi teatino". AfFó, I., Vita del Cardinale Sforza Pallavicino, Roma, 1845, p. 96 (contenida en el Tomo VII de la Biblioteca Clásica Sacra de Ottavio Gigli). Hecho que asimismo recoge el propio biógrafo de Tomasi: "il pijssimo Cardinale, poiché nel tempo della sua morte, gli assistette egli sempre, lo confortò in quell'ultimo passo, gli diede colle sue mani l'Estrema Untione, e finalmente morì nelle sue mani, con somma consolatione d'ambedue; del Cardinale per morire tra le mani, e assistenza d'un sì caro Amico..."; Bagatta, G. B., Vita del Ven. Servo di Dio D. Carlo de' Tomasi e Caro..., Roma, 1702, Cap. XXII [Ed. digital s/p: <http://www.infolio.it/tomasi.html $>$ ].

38 “AL PADRE DON CARLO TOMMASI CHERICO REGOLARE. LIBRO TERZO [...] Voi me ne siete stato il motore con l'autorità de' consigli; il promotore con la assiduità de' conforti; l'aiutatore con la santità de' ragionamenti; il corregitore con la perspicacità delle osservazioni, e con la fedeltà delle ammonizioni”, PALlavicino, S., Arte della Perfezion Cristiana, Roma, 1665, p. 287.

39 Así lo hace ver la correspondencia de Pallavicino, salpicada por mutuas muestras de afecto y continuas referencias a los dones - no siempre materiales- intercambiados con la familia Tomasi. Cfr. Lettere del Cardinale Sforza Pallavicino, Tomos I y II (XX de la Biblioteca Clásica Sacra de Ottavio Gigli), Roma, 1848. Las cartas dirigidas a Carlo pueden encontrarse en: pp. 35-37 (I) y 13-17 (II); las enviadas al Duque de Palma en: pp. 46-47 (I) y 60-91 (II).

40 Ibidem, pp. 46-47 (I): Carta enviada al Duque de Palma el 10 de octubre de 1666.

${ }^{41}$ Entre otras, las de san Traspadano, que hoy pueden venerarse en la Chiesa Madre de Palma di Montechiaro. Ibid., pp. 86-87 (II): Carta enviada al Duque de Palma el 16 de? de 1666. O las recibidas por legado testamentario del 
En cuanto a la relación habida entre Tomasi y el Caballero, el tenor parece ser el mismo. En el plano exclusivamente artístico, se conoce que Carlo, tan sólo cuatro años después del episodio del Crucifijo (esto es, en 1671), encomendó a Bernini la elaboración de un singular proyecto de suculentas significaciones: la transformación del Anfiteatro Flavio en Templo de los Mártires (el deterioro en que por entonces se encontraba el edificio y su indecorosa explotación comercial moverían al clérigo a esta iniciativa). Sus planes no vieron fructificar, sin embargo, Clemente $\mathrm{X}$ acogió algunas de sus lúcidas propuestas para proteger el magno Coliseo -elevadas al Pontífice en forma de memorial-, que quedó finalmente consagrado a la gloria de los mártires durante las celebraciones del Jubileo de $1675^{42}$. En el plano de lo personal, Bernini y Tomasi disfrutaron de una gran amistad, extensiva asimismo a sus respectivas familias ${ }^{43}$ : no en vano, Domenico Bernini, sexto hijo y segundo gran biógrafo del Caballero, dejó igualmente por escrito la vida del sobrino de Carlo, el Cardenal Giuseppe Maria Tomasi (canonizado en fecha reciente) ${ }^{44}$.

Retomando ya el objeto principal de nuestra investigación, el Crucifijo que había sido de Pallavicino, y ahora era propiedad de la familia Tomasi, muestra, respecto del español, similitudes exclusivamente formales: así se deduce de las palabras del propio teatino, que no sólo registra sus diferencias materiales (bronce vs. cartón-piedra) ${ }^{45}$, sino también cromáticas: en este sentido, la referencia al colorido de las carnaciones es prueba suficiente del carácter policromado que revistió el Crucificado, sin duda, una rara avis en la producción berniniana; sin embargo, la propia peculiaridad del material de ejecución y el hecho de que el artista guardase para sí y su familia -y durante más de diez años- este segundo Crucifijo, parecen explicar esta anomalía ${ }^{46}$. Larga posesión que justificaría cualquier intervención (admitiendo incluso un preliminar tratamiento a imitación) ya desde la óptica de la experimentación, ya desde su hipotética adaptación a unos usos devocionales más afectivos y personales. Volveré sobre estos particulares.

Por otro lado, no parece del todo clara la línea temporal seguida por sendos Crucifijos; la sucinta referencia modello del signor Cavaliere Bernino, conduce a pensar bien en un momento previo del proceso escultórico (aquel que llevó a la definitiva elaboración del bronce; esto es, el ejemplar en cartón-piedra actuaría en sentido estricto como modello), bien en una fase posterior a la consumación de los trabajos (remitiendo pues a una forma precedente, ya sea fuente de inspiración u objeto de reproducción). Imprecisión cronológica asimismo avivada por sendos informantes: el propio Tomasi, que refiere no sin traza de ambigüedad ciertos quehaceres subsecuentes (che l'ha fatto rifare più volte per renderlo più vivamente devoto), o Baldinucci, que parco manifiesta la ejecución de un'altro simile (referencia que en ningún caso cabe interpretar desde la perspectiva de la sucesión temporal, y sí de la dependencia respecto de un ejemplar noble) ${ }^{47}$.

Cardenal: "in contrasegno del suo affetto, gli lasciò due Reliquiarij, l'uno con la Reliquia di S. Tomaso di Villanuova, e l'altro con l'altra di S. Carlo [Borromeo]"; BagatTA, G. B., Op. cit., Cap. XXII [Ed. digital s/p].

42 Di Macco, M., Il Colosseo. Funzione simbolica, storica e urbana, Roma, 1971, pp. 82-84. Las vicisitudes de este proyecto pueden encontrarse en el Capítulo XXVI de la biografía de BAGATTA, Op. cit. [Ed. digital s/p].

${ }^{43}$ Cfr. por ejemplo la misiva de consolatione, ch'egli scrisse a Monsig. Bernini, suo amicissimo, quale si ritrovava travagliato da una longa infermità, contenida en: Ibidem, Cap. XIII [Ed. digital s/p].

${ }^{44}$ Bernini, D., Vita del Ven. Cardinale D. Gius. Maria Tomasi de'chierici regolari, Roma, 1722.

${ }^{45}$ Material que por otro lado se encuentra en consonancia -como se colige de las palabras de Montanari a propósito de un dibujo fatto a penna por el Caballero y poseído por el Cardenal- con el estricto respeto del voto de pobreza practicado por Pallavicino, che praticamente non disponeva di quadri o libri propri; MonTANARI, T., Op. cit., p. 49 in fine.

46 Obviamente, me refiero a una policromía de matiz naturalista; lejos de soslayar la riqueza cromática de los conjuntos escultóricos del artista. A propósito de esta cuestión capital: WiTTKOWER, R., La escultura: procesos y principios, Madrid, 1977, pp. 209 y ss.

$47 \mathrm{Y}$ en cualquier caso, los posteriores trabajos efectuados a instancia de Monseñor Bernini justificarían cualquier referencia a un momento subsiguiente. 
Y aunque un análisis atento de las circunstancias decantaría la balanza en favor de la primera de las posibilidades (esto es, la del modello di cartapesta, ya empleada por Bernini en otras prestigiosas empresas) (figs. 2-3 $)^{48}$, una segunda cita -en este caso extraída de la propia biografía de Tomasi- evitará las siempre escurridizas conjeturas; cita que no sólo abunda en algunos detalles consignados en la misiva, sino que clarifica igualmente los tiempos del proceso creativo: "volle il Cardinale anco mostrare in quell'ultimo [momento] il suo affetto verso D. Carlo, [entregándole] un Crocefisso di carta pista, fatto dal Cav. Bernino, per farne un altro di bronzo simile, da mandare al Re di Spagna Filippo IV, havendoglielo egli stesso in persona portato in Cella"49. La referencia parece suficientemente clarificadora; huelgo pues detenerme en su análisis.

Respecto del definitivo destino de la obra, que todavía el teatino conservaba en su celda -como recuerda este testimonio- y debía enviar a Palma di Montechiaro, informa oportunamente una segunda biografía, en este caso, la de la devotísima Duquesa Rosalia de Tomasi, que verifica la positiva recepción del Crucifijo (instalado en su cámara del Palacio Ducal) ${ }^{50}$, así como su ajustado acomodo a las sugerencias de su cuñado Carlo (dispuesto en el interior de una hornacina, oculto tras ricos cortinajes) $)^{51}$ :

"E perché voleva di continuo presente agli occhi come teneva sempre fisso nel cuore, l'amato suo Crocifisso [...], ne fece da Roma venire un'altra; di cui fu proveduta dal P. D. Carlo suo Cognato, la quale collocò nella sua camera medesima dentro d'un bel Tabernacolo, guernito di nobili cortine, avanti il quale faceva la pia Signora i suoi divoti esercizi, ed orazioni, accompagnate da copioso spargimento di lagrime".

Y hasta aquí la información relativa a este singular y largo tiempo escurridizo Crucificado, modelo de aquel celebradísimo ejemplar que Bernini elaboró para el Panteón de Reyes. Únicamente resta por examinar el quizá desconcertante tratamiento cromático aplicado a nuestra figura; examen que permitirá penetrar por entre el proceso escultórico, a la par que ponderar las obras ejecutadas en este envilecido material.

Ya se hizo referencia a la dificultad para precisar, sin otra apoyatura que la concisa referencia modello del signor Cavaliere Bernino, el instante en que nuestro ejemplar había sido ejecutado: previo (modelo sensu stricto) o posterior (reproducción o variante). Aun cuando la primera de las opciones se juzgaba la más plausible (y ajustada a término), ninguna alternativa parecía descartable, y así lo venía a corroborar el propio hacer coetáneo del artista y su taller. Apenas unos

48 Caso de dos de las estatuas de ángeles elaboradas para el Baldaquino de San Pedro, documentadas en los pagos realizados a dos de sus oficiales, y que reportan un saldo en favor de Bernini por los modelos de arcilla y "di Carta Pista per detto altare"; o el de los modelos para la Memoria de Sor María Raggi y el ya referido del Alma Condenada. En este caso, pese a las diferencias cromáticas que el modelo presenta respecto del ejemplar marmóreo, el profesor Salerno ha argüido que "potrebbe documentare una tappa progettuale intermedia, da collocare tra la versione in marmo e una prevista, ma mai realizzata, versione in bronzo [...] una 'prova per una eventuale traduzione dell'invenzione in quel materiale"'. Cit. en GALAssi, C., "Gian Lorenzo Bernini: Modello per l'Anima dannata", en AA.VV., La scultura in cartapesta. Sansovino, Bernini e il maestri leccesi tra tecnica e artificio, Milán, 2008, p. 90 [Ficha de Catálogo]. Cfr. SALERno, C. S., "Cartapeste di età barocca", en AA.VV., La scultura in cartapesta..., Milán, 2008, pp. 82-83. Por otro lado, el inventario de los bienes de estudio del escultor refiere asimismo dos obras realizadas en cartón-piedra: "un basso rilievo in carta pista indorata d'una Beata", identificable con el modelo para el medallón de Sor María Raggi, y "un basso rilievo di carta pista con una madonna indorata et inargentata tutta" de difícil atribución.

49 Bagatta, G. B., Op. cit., Cap. XXII [Ed. digital s/p]. La cursiva es mía.

${ }^{50}$ El mismo que empleó Visconti para las localizaciones de Donnafugata, trasunto literario de Palma di Montechiaro, en El Gatopardo; aunque he evitado la caprichosa referencia al celebrado escritor Giuseppe Tomasi di Lampedusa, el lector avisado habrá sabido reconocer su familiaridad con los primeros Tomasi.

51 Talstosa, A., Ragionamento Storico della Vita e Virtù dell 'Ill. Madre Suor Maria Sepellita della Concezzione... nel secolo chiamata Donna Rosalia Tomasi, Palermo, 1722, Cap. VIII [Ed. digital s/p: <http://www.infolio.it/tomasi.html>]. 
meses después de la terminación del bronce español, Girolamo Lucenti, discípulo de Bernini, fundía un nuevo Crucificado para Luis XIV (probable encargo y donación del Cardenal Antonio Barberini), de claras concomitancias con el escurialense ${ }^{52}$. Poco tiempo después, entre 1658 y 1660, un segundo colaborador, Ercole Ferrata, vaciaba para los altares de San Pedro hasta veinticinco pequeños Crucifijos siguiendo los diseños del maestro (uno, de un Cristo vivo, y otro, de uno muerto), vinculados -aunque vagamente- con el ejemplar español ${ }^{53}$. A estas prácticas de carácter seriado o inspirativo -que dificultaban una fundada elección-, venían a sumarse la propia historia de este singular material (la cartapesta) y sus obsequiosas características técnicas (esto es, su especial adecuación a la actividad reproductiva). Y entre tanta incertidumbre, todavía cabía desconfiar de los subsiguientes trabajos instados por Monsignor Bernino (¿a qué se refería Tomasi con aquel fatto rifare più volte...?), o de la insólita policromía aplicada al Crucificado (del todo infrecuente en la producción berniniana, aunque documentada y para este mismo médium en un caso coetáneo $)^{54}$, que se veía así desposeído de ciertas virtudes probatorias vinculadas a los modelos.

En efecto, cabe recordar que solía aplicarse a este tipo de obras tratamientos pictóricos que fingían el colorido y calidades de aquellos materiales escogidos para su definitiva elaboración (piénsese en el modelo cartáceo del medallón de la Memoria de la Beata Maria Raggi, hoy en el Palazzo Venezia de Roma) (fig. 2): a escala reducida, un modelo fingido podía dar al comitente una idea cabal de la obra que entonces aceptaba o rechazaba emprender; a escala natural, un tratamiento a imitación permitía al escultor una más ajustada valoración de las luces y las sombras, de las proporciones, de los puntos de vista, del general efecto que la versión definitiva debía producir. Y si no parecen pocas las ventajas descritas, todavía existía una última y nada desdeñable: un ejemplar de estas características, elaborado en un material de bajo coste, fácilmente manipulable y que admitía con toda comodidad tratamientos imitativos, evitaba el desafío de una quizá engorrosa fundición del bronce ${ }^{55}$. En caso de superar el examen, el producto final podía obtenerse de la misma matriz que el modelo. No parece improbable que nuestro modello aparezca interpuesto en estas fases últimas del proceso escultórico (admitida una presumible escala natural o próxima al natural $)^{56}$, ya contiguas al vaciado definitivo del bronce. Una prueba no necesariamente aceptada por Bernini, pues nada parece excluir la posibilidad de que el escultor se viese obligado a rechazar la hechura por cualquier causa -incluso por razón de sus más conservadores clientes-, no obstante valorar con satisfacción los resultados obtenidos, lo que sin duda explicaría la decisión de conservar consigo la pieza (quizá en previsión de futuras comisiones).

52 Semejanzas prontamente advertidas por Fagiolo dell'Arco - no obstante las diferencias de tamaño entre ambas obras: en altura, más de 30 centímetros-. Cfr. FAgiolo dell'ArCo, M., Berniniana. Novità sul regista del Barocco, Milán, 2002, pp. 112-119.

53 WitTKOWER, R. (1990), Op. cit., pp. 265-267. Un examen atento de éstas y otras imágenes cristíferas berninianas puede encontrarse en: Martineldi, V., "La 'Imago Christi' secondo Bernini. Costanti e varianti tipologiche e formali”, en Martinelli, V. (ed.), L’ Ultimo Bernini. 1665-1680, Roma, 1996, pp. 181-232.

${ }^{54}$ El de los cuatro putti "di carta pista grandi di color di carne, zazzere naturali e ghirlande di rose di seta" que adornaron el soberbio carro carnavalesco construido en 1658 para el nipote Agostino Chigi; un carro para el que se emplearon asimismo otros muchos elementos de cartón-piedra. FAGIOLO DELl'ArCo, M., La festa barocca, Roma, 1997, pp. 389-390. El profesor Fagiolo sugiere la más que probable colaboración de Giovan Paolo Schor en esta empresa.

55 Cfr. SAlERno, C.S., "Gianlorenzo Bernini: Modello per Suor Maria Raggi”, en AA.VV., La scultura in cartapesta..., Milán, 2008, pp. 94-97 [Ficha de Catálogo].

${ }^{56}$ Respecto del tamaño que debió tener nuestro ejemplar, cabe pensar, siendo exclusivamente formales las similitudes entre Crucifijos, en una escala 1:1 o aproximada. Y aunque la referencia de Tomasi a un tabernáculo cubierto puede llevar a pensar en unas dimensiones más reducidas, en realidad, una hornacina de poco más de 1 metro y 40 centímetros no parece, ni mucho menos, desproporcionada. 


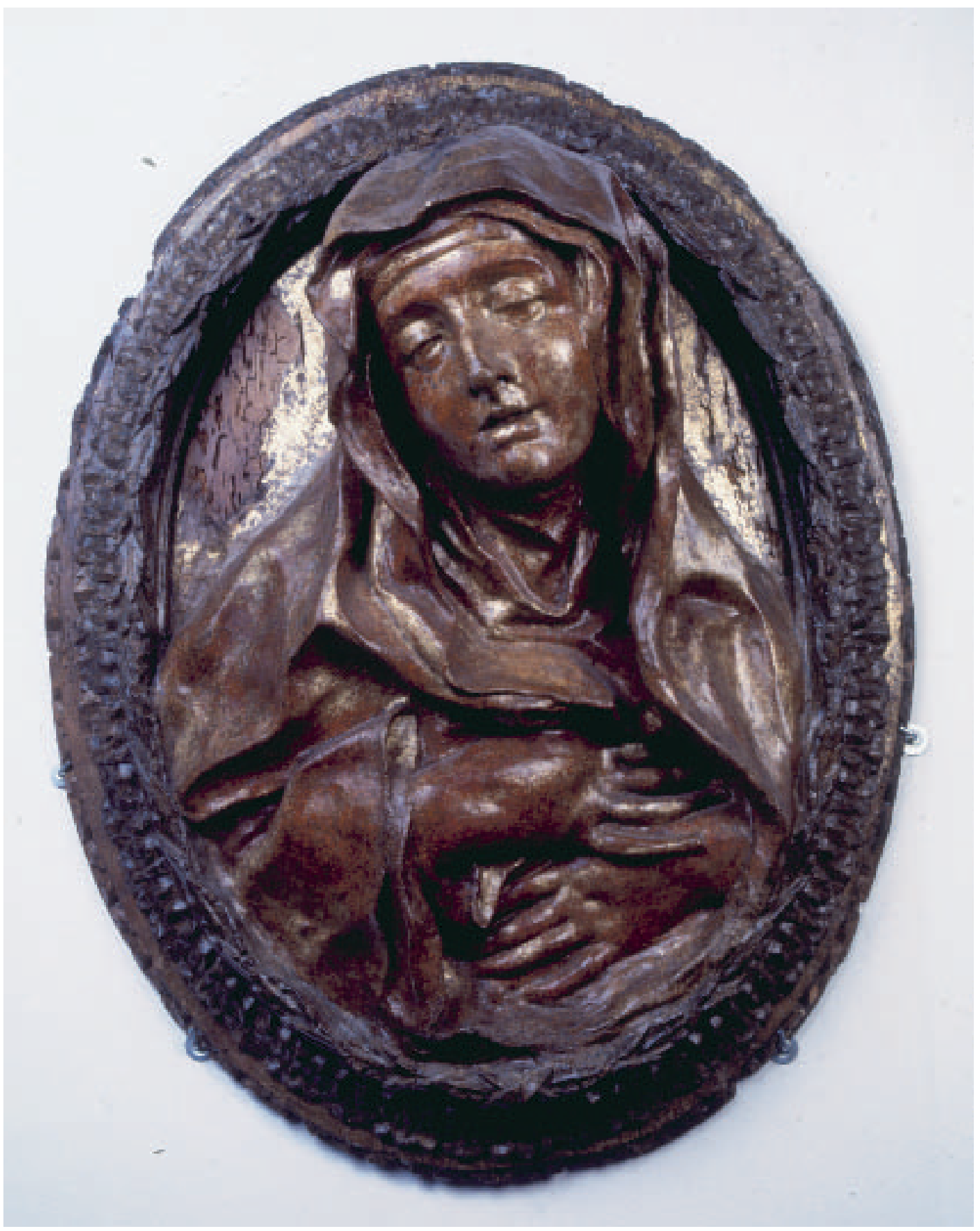

Fig. 2. G. L. Bernini. Modelo de la Memoria de la Beata Maria Raggi. Cartapesta.

Museo Nazionale del Palazzo di Venezia. Soprintendenza Speciale per il Patrimonio Storico, Artistico ed Etnoantropologico e per il Polo Museale della città di Roma. 


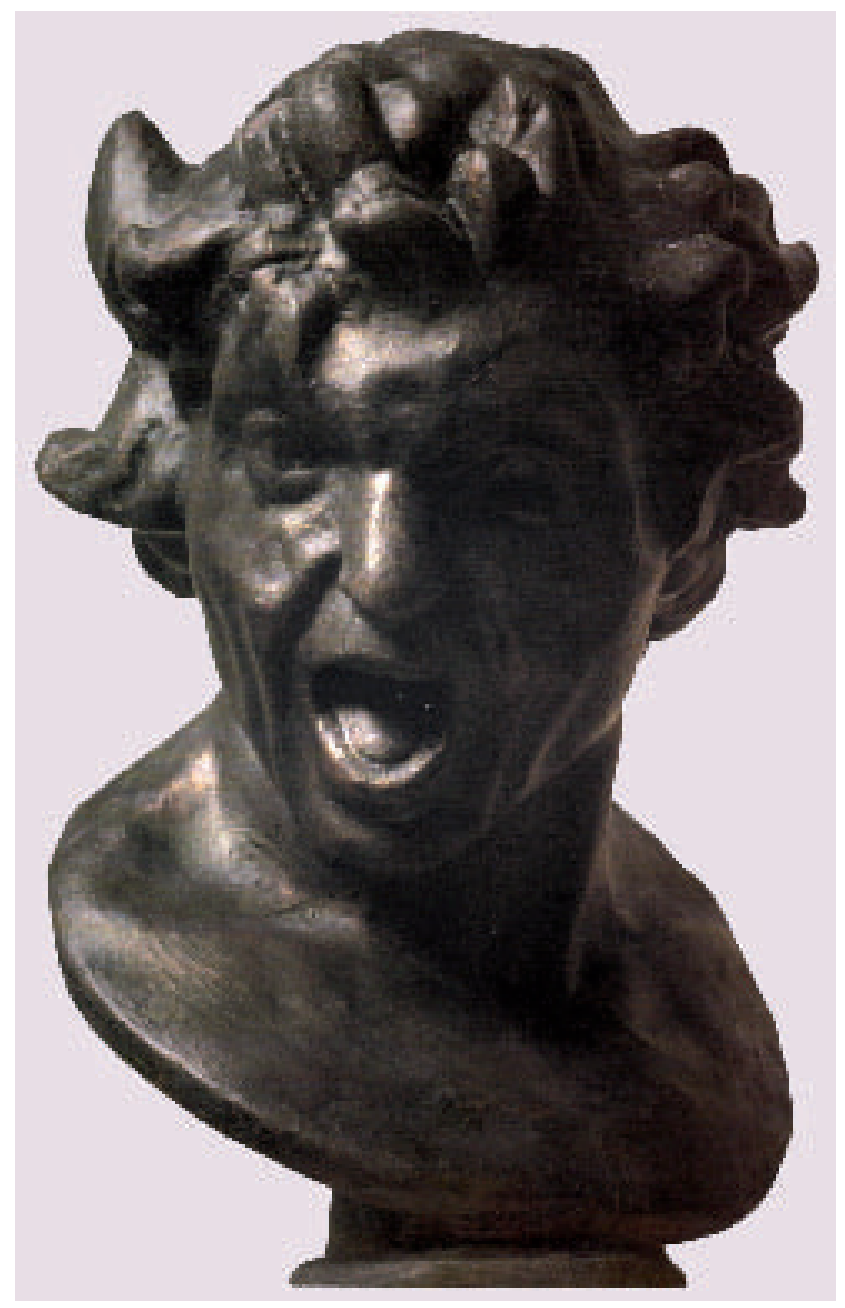

Fig. 3. G. L. Bernini. Modelo del Alma Condenada. Cartapesta. Museo di Palazzo della Penna. Perugia.

Sólo entonces, una vez finalizado el proceso de elaboración del ejemplar noble, toda vez que la cartapesta dejó de funcionar como modello, el Crucificado debió recibir el singular tratamiento de policromía; sentido éste en que cabe entender el fatto rifare per renderlo più vivamente devoto a que se refiere Carlo de Tomasi (a nadie escapan las ventajas que en lo devocional puede proporcionar la policromía; y que fuese Monsignor Pier Filippo el promotor de la transformación parece cooperar en esta interpretación). Por lo demás, existen conocidos ejemplos de reutilización de modelos; modelos que, una vez obtenida la versión noble y aparentemente desprovistos de una futura utilidad, eran lujosamente policromados para su inserción en el mercado artístico (término éste en el que difieren del ejemplar berniniano: el hecho de conservar para sí, y durante más de diez años, el Crucifijo, destierra cualquier pretensión comercial; con todo, los casos de reciclaje informan de un quehacer nada infrecuente, la conversión cromática de los modelli): sirva de ejemplo el modelo en tierra cruda de un Crucificado de Algardi, transformado en obra autónoma mediante la aplicación de una muy cuidada policromía, y después entregado 
a la Iglesia de Santa Marta de Roma (en la actualidad, conservado en la capilla del Palacio de la Gobernación de la Ciudad del Vaticano $)^{57}$.

Por otro lado, no parece fácil determinar -o quizá sea innecesario- el responsable de los trabajos de policromía del Crucificado Tomasi; labores generalmente confiadas a miembros del taller o eventuales asistentes. Podría pensarse, dada la calidad ejecutiva sugerida por las palabras del clérigo -aunque sin otro apoyo que la intuición- en el pintor y decorador austriaco Giovan Paolo Schor, activo colaborador del Caballero en un sinfín de empresas efímeras desde la década de $1650^{58}$. A su método de trabajo conjunto se refirió Fagiolo dell'Arco, extractando unas palabras del conocido diario de Chantelou a propósito del austriaco: "De él [Schor] dijo el Caballero que dominaba muy bien el dibujo; y que para las comedias y teatros hacía falta un hombre que tuviera inventiva e ideas felices [el propio Bernini], pues, tendiendo eso, podía hacerse ayudar por alguien que coloreara sus ideas, y por otro que fuera experto en tramoyas"

Sea como fuere, todas estas conjeturas son indicativas de un problema mayor para la investigación, a saber: la dificultad para determinar la cronología, concretar la naturaleza o asignar una autoría - precisar el valor real de un trabajo en buena parte ejecutado por los miembros de una bodega- de las formas vinculadas o derivativas de un noble ejemplar ${ }^{60}$.

En cualquier caso, y pese a lo insólito que a priori pueda resultar el médium utilizado, no debe minusvalorarse la producción de obras ejecutadas en cartón-piedra (o cualesquiera otros materiales modestos: yeso, estuco, arcilla, terracota, estopa, cera, cuero prensado, tejidos). Y no debe hacerse por razón de su inclinado carácter seriado o derivativo, pues no siempre adoptaron este perfil y, en todo caso, vinieron a constituir una parte importante de la producción de los más reputados talleres italianos, implicando a personalidades tan eminentes como Ghiberti, Donate$10^{61}$, Della Robbia, Agostino di Duccio, Desiderio da Settignano, los Rossellino, Benedetto da Maiano, Bartolomeo Bellano, Neroccio de'Landi, Giovan Francesco Rustici, Jacopo Sansovino, Alessandro Vittoria, Francesco Segala, Pietro y Ferdinando Tacca (fig. 4) ${ }^{62}$, o los ya referidos Algardi y Bernini. Tampoco por razón de la vileza o tosquedad del material ejecutivo, resultado de una anquilosante superposición de criterios materiales por sobre los estéticos, curiosamente no aplicable cuando el historiador se refiere al magnificente aparato de la fiesta barroca. En este sentido, y a la luz de la significativa producción sobrevivida, de las personalidades comprometi-

57 SAlERno, C. S., Op. cit., p. 82.

58 Ya se apuntó su probable colaboración en el caso del Carro Chigi: Vid. supra, nota 54.

59 Fagiolo dell'Arco, M. (1997), Op. cit., p. 407. La cita ha sido extraída de la edición española del Diario: Chantelou, P. F., Diario del viaje del Caballero Bernini a Francia, Madrid, 1986, p. 244.

${ }^{60}$ Un ejemplo de la dificultad para precisar la naturaleza y tiempos de un ejemplar derivativo o vinculado lo proporciona una hermosísima Magdalena en éxtasis de Algardi: el ejemplar en bronce se conserva en la Basílica de la Magdalena en St. Maximin Le Saint Baumen, en la Provenza; pero también han sobrevivido una serie de ejemplares en terracota y cartón-piedra (Museo Cívico de Perugia; Colección privada), obtenidos no a partir del molde de la pieza broncínea sino de la contraforma de un modelo probatorio, seguramente ejecutado en barro cocido. La supervivencia de varios ejemplares y el cuidado carácter de sus policromías, son indicativas de la manifiesta intención de hacer introducir estos objetos en el mercado artístico. GALASSI, C., "Alessandro Algardi: Maddalena in estasi", en AA.VV., La scultura in cartapesta..., Milán, 2008, pp. 88-89 [Ficha de Catálogo].

${ }^{61}$ Un Donatello que "dilettandosi d'ogni cosa, a tutte le cose mise le mani, senza guardare ch'elle fossero vili o di pregio"; VASARI, G., Le vite dei più eccellenti pittori, scultori e architetti, Roma, 2007 (ed. íntegra), p. 360; la cursiva es mía. El florentino experimentó sin distinción con todos los materiales disponibles: estuco, terracota, cera, yeso, vidrio, cuero prensado y por supuesto cartón-piedra.

${ }^{62}$ En la Iglesia de Santa Maria de Settignano se conserva un magnífico Crucificado de cartón-piedra formalmente vinculado a otro de los ejemplares broncíneos de El Escorial, el de Pietro Tacca. AA.VV., Il Crocifisso di Pietro Tacca a Settignano. Restauro di un'inedita cartapesta policroma, Florencia, 2001. 


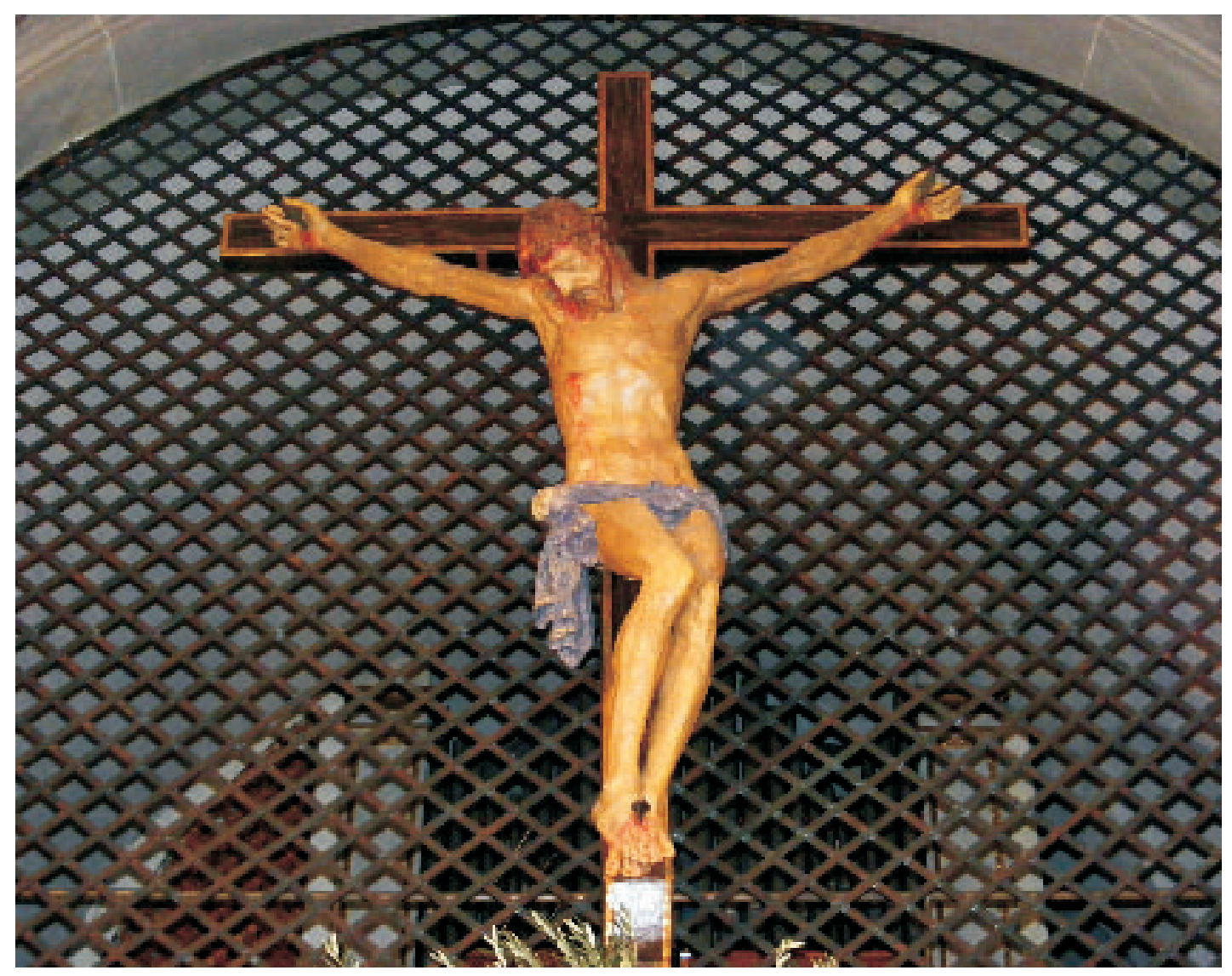

Fig. 4. P. Tacca. Cristo Crucificado. Cartapesta policromada. Sta. Maria Asunta. Settignano. Fotografía cortesía de Belén García Piñero (Polo Museale Fiorentino).

das en su explotación, de los laudatorios comentarios extraídos de las más acreditadas fuentes ${ }^{63}$ o del experimentalismo que en ocasiones comportó su empleo ${ }^{64}$, conviene revisar la validez $\mathrm{u}$

63 Sirvan de ejemplo los encomiásticos comentarios vertidos por Tomasi a propósito de la obra aquí referida; pero también los de Pietro Aretino respecto de la célebre Madonna de Vittorio Veneto de Jacopo Sansovino (Lettere sull'arte, Milán, 1957, Carta DCXXV); los de Vasari en relación al atrevido y modernísimo retrato ecuestre ideado por Beccafumi con ocasión de la visita a Siena del Emperador Carlos (Op. cit., p. 915); o los del propio Baldinucci a propósito de la "meravigliosa figura di Christo Nostro Signore, fatta come si dice di carta pesta [...] per la Chiesa di San Rocco di Massa", obra modelada por Felice Palma, de tal belleza que el mismísimo Pietro Tacca "ne oferisse a' fratelli più centinaja di scudi, coll' obbligo ancora di farne loro una copia di Bronzo di sua mano" (BAldinucCI, F., Notizie de' professori del disegno di Cimabue in qua, Tomo X, Florencia, 1771, p. 133).

${ }^{64}$ Vid. supra, nota 61. En este sentido, conviene referirse a la singular figura del tallista y plasticatore Romano Alberti, Il Nero da Sansepolcro, personalidad recientemente recuperada por la historiografía artística, y que hizo de la experimentación polimatérica su campo de especialización. Su bodega se orientó fundamentalmente a la producción de imágenes devocionales de inequívoco éxito, elaboradas por agregación, en torno a un armazón de madera consolidado con clavos metálicos, de materiales diversos y asombrosamente pobres (entre éstos, la cartapesta), hábilmente manipulados, modelados y policromados, obteniendo al término productos de alta calidad y distinguida apariencia. GALASSI,

Arch. esp. arte, LXXXIV, 335, JULIO-SEPTIEMBRE 2011, 211-226, ISSN: 0004-0428 
operatividad de esta vieja jerarquía ${ }^{65}$. Como indica el profesor y restaurador Carlo Stefano Salerno, "tuttavia, nel Seicento la scultura in cartapesta non era ancora universalmente ritenuta propria di un livello artistico secundario, obbedendo a un principio universale di gerarchia delle tecniche artistiche che collocava in maniera rigida i materiali nobili come il marmo o il bronzo al vertice e alla base quelli che possiamo definire materiali poveri" ${ }^{\prime 66}$.

Fecha de recepción: 29-IV-2010

Fecha de aceptación: 13-VII-2010

C., "Arte e serialità nella bottega di Nero Alberti da Sansepolcro", en AA.VV., Sculture "da vestire". Nero Alberti da Sensepolcro e la produzione di manichini lignei in una bottega del Cinquecento, Milán, 2005, pp. 15-104.

${ }^{65}$ En éste, como en los restantes sentidos referidos, remito a un próximo artículo que en la actualidad ultimo; o a los muy completos estudios llevados a cabo en Italia y que han tenido su culminación en la reciente y magnífica exposición, La scultura in cartapesta. Sansovino, Bernini e il maestri leccesi tra tecnica e artificio (la cita bibliográfica ha sido reiteradamente referida).

${ }^{66}$ Salerno, C. S., Op. cit., p. 81. 